\section{Structural and Morphological Control of Cationic Surfactant-Templated Mesoporous Silica}

\author{
HONG-PING LIN ${ }^{\dagger}$ AND CHUNG-YUAN MOU*,‡
}

Institute of Chemistry, Academia Sinica, Taipei, Taiwan 115, and Department of Chemistry and Center of Condensed Matter Science, National Taiwan University, Taipei, Taiwan 106

Received J uly 9, 2001

\section{ABSTRACT}

Micelle-templated mesoporous silica materials are rapidly becoming important in many fields of chemistry for hosting reactants or catalysts in confined space. Fine control of the pore size, wall structure, surface functionalization, defects, and morphology is needed for fine-tuning the pores as nanoreactors. We review the physical chemistry of solution silicate species and surfactants in the synthesis of mesoporous silicas. Controls in surfactant packing and liquid crystalline phase transformation can lead to various tailored synthesis strategies. Postsynthesis treatments further make more stable mesoporous materials.

\section{Introduction}

It has been a decade since the discovery of micelletemplated mesoporous silica (MMS) materials. ${ }^{1}$ Recent developments have been reported on their versatile applications in catalysis, separation, drug delivery, nanocomposites, and confinement of electronic materials. ${ }^{2}$ These demand precise control of the pore size, accessibility, stability, morphologies, and surface functionalization of the mesoporous silicas. However, approaches to their synthesis and modifications are rather rich, and a fundamental understanding of the underlying physical chemistry of self-assembly is far from complete. It is desirable to integrate our knowledge of amphiphiles in solution, membrane physics, and sol-gel chemistry to build a framework for understanding such systems.

When a silica source is combined with an ionic surfactant, such as cetyltrimethylammonium bromide (CTAB)

Hong-Ping Lin received his B.S. and M.S. degrees in chemistry from National Cheng Kung University (Tainan, Taiwan), and earned his Ph.D. in chemistry from National Taiwan University in 1997. From 1998-2002, he was an Academia fellow at the Institute of Chemistry, Academia Sinica, Taiwan. In August 2002, he became assistant professor at National Cheng Kung University.

Chung-Yuan Mou earned his Ph.D. in theoretical chemistry from Washington University in Saint Louis, Missouri, in 1975. After postdoctoral research, he returned to National Taiwan University in 1978. At present, he is National Chair Professor of Chemistry. In theoretical chemistry, he worked on the theory of electrolytes, nonequilibrium statistical mechanics, structure and dynamics of water, and quantum M onte Carlo. Since 1993, he has shifted his research interests to experimental studies of advanced materials. This includes the chemistry of $\mathrm{C}_{60}$ and carbon nanotubes. In the past five years, his major research efforts have been focused on mesoporous molecular sieves, including the synthesis of new morphologies and catalytic applications. in solution, the self-organization process is complicated, involving silicate speciation reactions, surfactant/ silicate self-assembly, and transformation of mesophases. Scheme 1 shows the aggregation processes driven by the silica condensation process. These processes are sensitive to $\mathrm{pH}$, temperature, aging time, counterions, and surfactants, as indicated in parentheses in Scheme 1.

From III to IV in Scheme 1, there is a continuous adjustment of the charge-matching at the surfactant/ silicate interface. The extent of surface charge-matching determines the curvature of the interface, and hence the mesostructure.

Packing and Charge-Matching of the Surfactant Molecules. We start with condition III in Scheme 1. The importance of surfactant structure in determining the mesophase architecture can be elucidated by using the concept of packing constraints. ${ }^{3}$ The evolution of the surfactant organization can be understood by looking at the packing parameter, $\mathrm{g}=\mathrm{V} / \mathrm{la} \mathrm{a}_{0}, 4,5$ where $\mathrm{V}$ is the volume of the hydrophobic surfactant chains, I is the surfactant chain length, and $a_{0}$ is the effective area of the hydrophilic headgroup of the surfactant molecule at the interface. This simple parameter can serve as a guiding rule to rationalize the product mesostructures in synthesis. From a highly curved to lamellar $\left(L_{\alpha}\right)$ structure, the $g$ value increases in the order $\mathrm{L}_{1}$ (spherical micelle, $\mathrm{g}<1 / 3$ ) $<\mathrm{N}_{\mathrm{c}}$ (nematic, explained later) $<\mathrm{H}_{1}$ (hexagonal, $\mathrm{g}=1 / 3_{3}-1 / 2$ ) $<\mathrm{V}_{1}$ (cubic, $\left.\mathrm{g}=2 /{ }_{3}-3 / 4\right)<\mathrm{L}_{\alpha}$ (lamellar, $\mathrm{g}=1 / 2-1$ ).

For the surfactant/ silicate system considered here, two dominating factors decide the surfactant packing: one is the charge-matching between surfactant headgroup and silanolate or charged silanol $\left(\mathrm{Si}-\mathrm{O}^{-}\right.$or $\left.\mathrm{Si}-\mathrm{OH}_{2}{ }^{+}\right)$at the interface, and the other is the organic chain packing. High silica surface charge-neutralizing surfactant charges, resulting in lower surface area per headgroup, lead to higher $g$ values. On the other hand, longer hydrophobic groups also give higher $\mathrm{g}$ values. Charge-matching is mainly controlled by $\mathrm{pH}$, cosurfactant, and counterion, and organic packing is influenced by temperature (tail motion) and organic additives. In alkaline conditions, the anionic silicate species condense at the surface of the cationic surfactant through strong Coulomb interactions $\left(\mathrm{S}^{+} \mathrm{I}^{-}\right)$. Structure-wise, charge-matching at the interface can be controlled most easily by $\mathrm{pH}$ changes. For example, $\mathrm{C}_{\mathrm{n}} \mathrm{TM} \mathrm{AB} /$ silicate $\left(\mathrm{C}_{\mathrm{n}} \mathrm{TM} \mathrm{AB}=\right.$ alkyltrimethylammonium bromide) tends to form a lamellar phase at room temperature for $n \geq 18$ and $\mathrm{pH} \geq 11$. Other examples are $M C M-41$ versus MCM-48. For the CTAB/ sodium silicate system, Pinnavaia et al. reported that MCM-48 could be made by simply controlling the alkalinity. ${ }^{6}$ Again, higher $\mathrm{pH}$ leads to MCM-48 of lower curvature structure. Recently, Tolbert et al. showed, by time-resolved X-ray diffraction, that surfactant packing is the main driving force of phase transformation in hydrothermal conditions. ${ }^{7}$

\footnotetext{
* Corresponding author. Tel.: 886-2-3366-5251. Fax: 886-2-2366-0954 E-mail: cymou@ccms.ntu.edu.tw.

+ Academia Sinica.

₹ National Taiwan University.
} 
Scheme 1

$\begin{array}{ccc}\text { Solution Process } & \text { Ion Exchange } & \text { Aging+Hydrothermal } \\ (\mathrm{pH}, \text { counterions, } \mathrm{T}) & \text { (counterions, silica source) } & (\mathrm{pH}, \mathrm{T}, \mathrm{P}, \text { aging time })\end{array}$

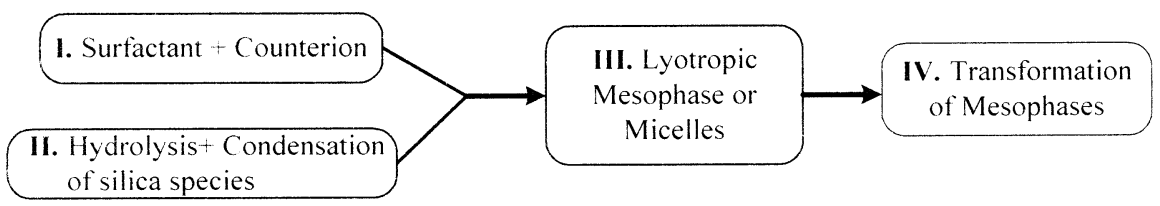

Degree of silica condensation increasing

On the other hand, in acidic synthesis below the isoelectric point of silica, the cationic silica precursor $\left(\mathrm{I}^{+}\right)$ formed at $\mathrm{pH}<2$ combines with $\mathrm{S}^{+} X^{-}$-type active sites in the surfactant aggregates through a weaker electrostatic interaction $\left(\mathrm{S}^{+} \mathrm{X}^{-} \mathrm{I}^{+}\right)$. When neutral surfactants $\left(\mathrm{S}^{0}\right)$ are employed, the hydrogen boding in $\mathrm{S}^{0}{ }^{0}$ can also stabilize the surfactant/ silicate aggregates. Examples are hexagonal mesoporous silica (HMS) materials ${ }^{8}$ from alkylamine and SBA-15 materials ${ }^{9}$ from amphiphilic copolymers $\mathrm{EO}_{20} \mathrm{PO}_{70}$ $\mathrm{EO}_{20}$.

\section{Interactions between Surfactants and Silicate Species}

In synthesis processes, there are at least three kinds of charged species in solution: silica species $\left(\mathrm{I}^{-}\right.$or $\left.\mathrm{I}^{+}\right)$, cationic surfactant $\mathrm{S}^{+}$, and its counterion $\left(\mathrm{X}^{-}\right)$. Their interactions depend on the silicate oligomeric species present because their charge densities depend on the degree of oligomerization. With strong enough interaction, the silicate ions exchange onto the micellar interface, and the local enriched concentration results in accelerated condensation of the silicate species.

A. Changes of Acidity of Silicate Species with Polymerization. First, we can start by asking a simple question: Why do cationic surfactant and silica form nanocomposites in alkaline synthesis in the first place? This is crucially related to the increasing acidity of silicate oligomers as they grow. For monomeric $\mathrm{Si}(\mathrm{OH})_{4}$, the $\mathrm{pK}_{\mathrm{a}}$ value is about 9.8 at room temperature, but it shifts to 6.5 gradually as siloxane condensation progresses. ${ }^{10}$ The higher oligomers become more acidic and thus more charged and competitive in exchanging the micellar counterion $\mathrm{X}^{-}$.

$$
\mathrm{S}^{+} \mathrm{X}^{-}+\mathrm{I}^{-} \rightleftarrows \mathrm{S}^{+} \mathrm{I}^{-}+\mathrm{X}^{-}
$$

The hydrolysis and condensation rate of the silica species are $\mathrm{pH}$-dependent. As shown in Figure 1, at $\mathrm{pH}$ lower than the isoelectric point ( $\mathrm{pH} \sim 2$ ), the condensation is acid-catalyzed and becomes faster as the $\mathrm{pH}$ decreases. At $\mathrm{pH}>2$, the condensation rate increases with $\mathrm{pH}$ until 8 and then decreases again. The particles of MMS made in acidic conditions tend generally to be bigger than MMS particles made in alkaline conditions..$^{11,12}$ This is due to the slower nucleation rate (cf. Figure 1) in acidic conditions. In acidic conditions, silica species are less condensed linear oligomers, while in alkaline solution the

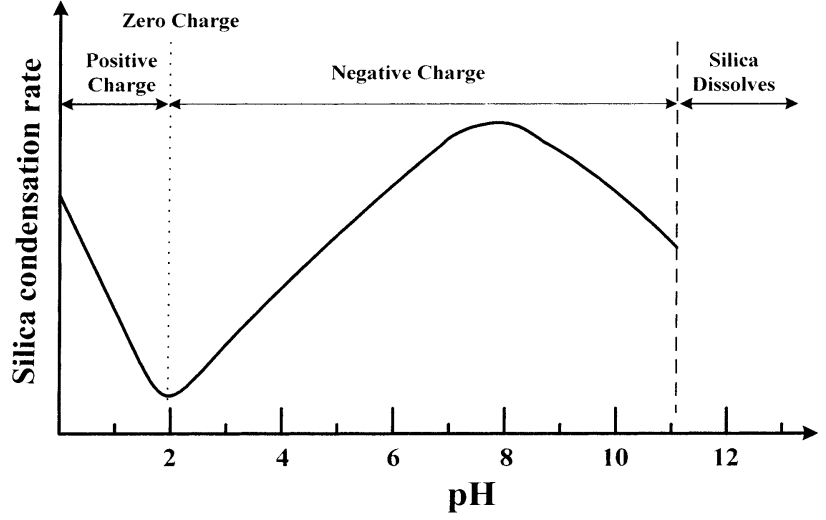

FIGURE 1. Effects of $\mathrm{pH}$ value on the silica condensation rate and silicas surface charge properties.

silica species are more cross-linked clusters. The acidmade MMS particles thus appear to be softer (weaker surfactant-silicate interaction) and stickier (more surface silanol), resulting in richer morphologies. In alkaline conditions, one could often obtain small submicrometersize particles.

By carefully controlling the $\mathrm{pH}$, we are able to development a rich variety of hierarchical ordered MMS from a "delayed neutralization" approach. ${ }^{13-15}$ In a specially designed alkaline synthesis of MCM-41, the initial pH of sodium silicate solution is fairly high $(\mathrm{pH}=11-12)$. This leads to highly charged anionic silicate species in solution and a lower rate of condensation. It has the advantage of separating silicate/ surfactant assembly and silica condensation. The initially homogeneous silicate/ surfactant solution can phase-separate into a dense lyotropic crystalline phase, which leads to hierarchical structures such as tubules-within-tubule (TWT) or pillar-within-sphere (PWS), as shown in Figure 2. This is possible because of the low extent of silica condensation in the soft surfactant/silicate self-assembly, and micrometer-scale reorganization becomes controllable. After the hierarchical soft structure is formed, "delayed neutralization" brings the $\mathrm{pH}$ to a lower value, in the range of 8-9, without the formation of an amorphous silica phase. The lower $\mathrm{pH}$ leads to further silica condensation and thus a thicker wall (ca. 1.7 $\mathrm{nm}) .{ }^{16,17}$ In fact, the $\mathrm{pH}$ is low enough that as-synthesized materials can be directly calcined without the collapse of the mesostructure. ${ }^{18}$ For similar reasons, repeated $\mathrm{pH}$ adjustments often lead to a more stable MCM-41 material. ${ }^{19}$ 


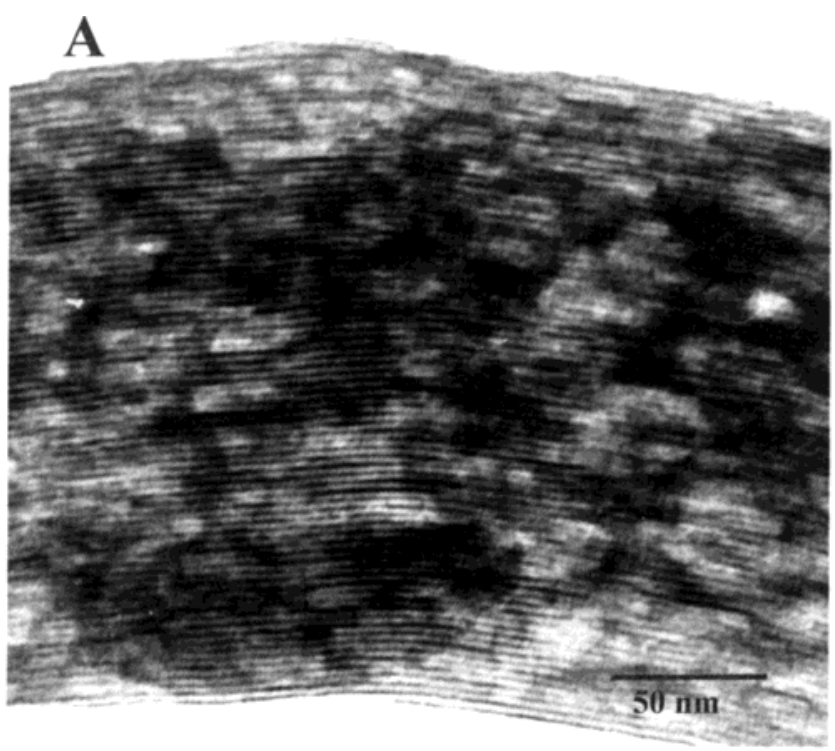

In the synthesis mixture, silicate polymerization can occur either at the surfactant/ water interface or in solution. The competition with the $\mathrm{X}^{-}$anions to bind with micelles depends on the relative binding ability of the silicate anion species with respect to the counterion (eq 1). Again, let us consider the example of synthesizing MCM-41 by using tetraethoxysilane (TEOS). At a fixed concentration of the salts, the rate of formation of mesostructure increases in the order $\mathrm{ClO}_{4}{ }^{-}<\mathrm{NO}_{3}{ }^{-}<\mathrm{Br}^{-}$ $<\mathrm{SO}_{4}{ }^{2-}, \mathrm{SO}_{3}{ }^{2-}<\mathrm{Cl}^{-}<\mathrm{F}^{-} .21$ The order in rates reflects the strength in counterion binding of $\mathrm{X}^{-}$to micelles. The more strongly adsorbing $\mathrm{X}^{-}\left(\mathrm{ClO}_{4}^{-}\right.$the strongest versus $\mathrm{F}^{-}$the weakest binding) would block the adsorption of silicate ions on micelles and delay the formation of the silica/surfactant mesophases (measured by induction period). The order of the ion series in $\mathrm{X}^{-}$agrees with the Hofmeister series in many lyotropic systems, such as ionprotein and ion-surfactant interactions. ${ }^{22} \mathrm{~A}$ different counterion would exchange the oligosilcate species at different stages of polymerization. This affords us a way of controlling the nucleation rate. Understanding this, choosing a proper counterion and reaction time would allow one to control the structure and morphology.

From Scheme 1, one can further separately evolve silicate or surfactant self-organization to a greater extent than by simple mixing of the surfactant solution and silica source. In a recent development, the separate evolutions of silicate oligomers are exploited prior to mixing of the surfactant and silicate source. Xiao et al. made mesoporous silica with hexagonal structure, possessing high acidity and hydrothermal stability. ${ }^{23}$ They used TEAOH to separately develop a zeolitic nanocluster as a silica precursor to make the mesoporous materials with cationic surfactant. In fact, previously Cheng et al. were able to make MCM-41 with higher hydrothermal stability with the use of TPA ${ }^{+}$as co-templating ion. ${ }^{24}$ The underlying process is probably the same: the success relies on formation of a better structured wall with preformed silicate oligomers.

C. Acidic Synthesis of Mesoporous Silica. In acidic media $(\mathrm{pH}<2)$, the positively charged silica oligomers cannot combine directly with positive surfactant. For charge balance, there must exist a bridge counterion $\left(\mathrm{X}^{-}\right)$ at the interface of silicas and surfactants. We thus formulated a kinetic model, where the $\mathrm{H}^{+}$and the surface of the surfactant aggregate $\left(\mathrm{S}^{+} \mathrm{X}^{-}\right)$catalyzes the silica condensation, to explain the rate variations of the surfactant/ silica precipitate formation versus both $\left[\mathrm{H}^{+}\right]$and $\left[\mathrm{X}^{-}\right]$ species. ${ }^{25}$ It is found that the binding of counterion $X^{-}$ determines the ensuing condensation reaction of cationic silicate species. Again, the induction rate follows the Hofmeister sequence: $\mathrm{NO}_{3}{ }^{-}>\mathrm{Br}^{-}>\mathrm{Cl}^{-}>\mathrm{SO}_{4}{ }^{2-} \approx \mathrm{F}^{-}$, with nitrate being the fastest case. The fact that $\mathrm{X}^{-}$ions mediate on the micellar interface more than in alkaline synthesis affects the structure order and morphology of the product more strongly.

In acidic synthesis, the silica is usually less condensed (smaller $\mathrm{Q}^{4}$ peak in ${ }^{29} \mathrm{Si} \mathrm{NMR}$ ), and the structure order is thus softer (allowing more disclinations) and often leads to rich morphologies (such as film, fiber, and gyroid). ${ }^{26-28}$ 


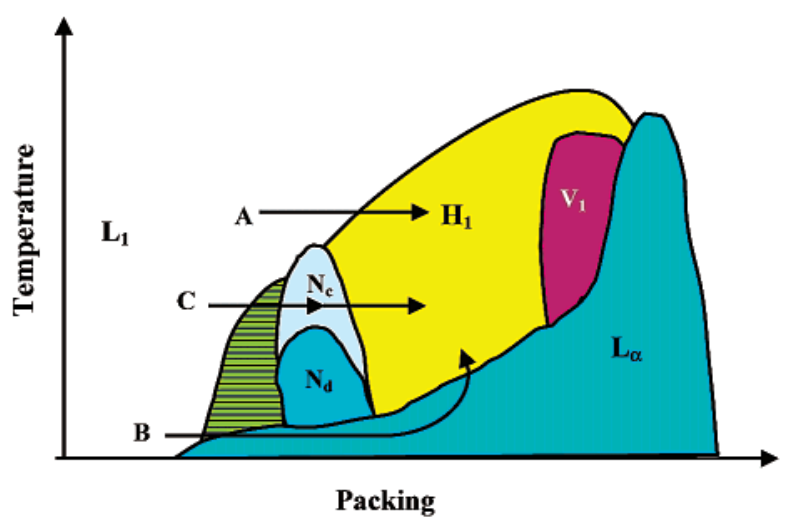

FIGURE 3. Schematic composite phase diagram of the surfactant/ silica organization in aqueous solution. $L_{1}$, micellar solution; $N_{c_{1}}$ nematic phase; $\mathrm{H}_{1}$, normal hexagonal phase (M CM -41; SBA-15); $\mathrm{V}_{1}$, normal bicontinuous cubic phase (MCM-48); $L_{\alpha}$, lamellar phase (M CM -50). Path A, the micellar solution route; path $B$, the lamellar phase route; path $C$, the nematic phase route.

Because of the weaker $\mathrm{S}^{+} \mathrm{X}^{-} \mathbf{I}^{+}$interaction in acidic synthesis, surfactants can be removed by extraction, which leads to higher silanol density on its internal wall.

In contrast to alkaline synthesis, where one can separately evolve silicate species, in acidic synthesis one can evolve the surfactant mesophase first and then use the structure as a template. Because of the weaker surfactantsilicate interaction here, the original liquid crystalline phase can be preserved when mixing with silica sources. When using neutral surfactants as templates, Coleman and Attard could directly mix lyotropic mesophase of the Brij 56 surfactant with silicates to obtain the mesostructured surfactant/silicate composite. ${ }^{29}$ Monolithic mesoporous materials can be made this way with Pluronic copolymers $^{30}$ or Brij 56 surfactant. However, for ionic surfactants, one can only delay the silica condensation as much as possible by letting the surfactant/silicate mesophase evolve first. This will be reviewed in the next section.

\section{Phase Transformation of the Surfactant/ Silicas Mesostructures in Synthesis}

We show a schematic phase diagram of the surfactant/ silicate/ water system in Figure 3, which gives a qualitative description of the lyotropic system of quaternary ammonium surfactant + salt. The $x$-axis could be any variable that increases the packing of surfactants in aggregation, such as the local concentration of surfactant or salt. When the salt is silicate, the system is a nonequilibrium one driven by silica condensation, and its structure evolves from state to state on the phase diagram. This is a composite phase diagram intended only to describe the synthesis space heuristically. During the synthesis process, the liquid crystalline state can transform into many different lyotropic mesophases before complete condensation of silicates solidifies the composite. Note here that the word "lyotropic" refers to the solvent system containing silicate ions.
For nonionic surfactant such as Pluronic copolymers, the phase behavior is more thermotropic than lyotropic. Figure 3 does not apply well in these cases. However, for the synthesis of $C_{n} T M A B$, Figure 3 is a good way to organize our understanding of the self-assembly process. We can classify the synthesis of the mesostructured surfactant/ silicate composite into three different routes, as follows.

Path A. The Micellar Solution Route. In standard synthesis of composites for M CM-41, the silicates species is sodium silicate and the surfactant concentration is low (even close to the critical micelle concentration). The starting oligomer silicate species possess low charge density, and then they gradually condense into highly charged multidentate oligomers and induce a transition from the $L_{1}$ to the $\mathrm{H}_{1}$ phase (MCM-41). Hydrothermal treatment leads to a better ordered $\mathrm{H}_{1}$ phase. This route was first proposed by Chen et al., ${ }^{31}$ and it usually leads to well-ordered microcrystals of MCM-41. Most of the faceted crystals of MCM-41 reported are synthesized by this route.

When a medium-chain alcohol is added as a cosurfactant in making MCM-41, it is incorporated in the micelle to increase the packing parameter $\mathrm{g}$ (increasing $\mathrm{V}$ and decreasing $\mathrm{a}_{0}$ ). This helps elongate the cylindrical micelle, which in turns leads to better cylinder packing in the hexagonal phase. ${ }^{32}$ We use 1-alkanol to improve the structure order of MCM-41 for short $C_{n} T M A B$. Also, using a surfactant mixture can fine-tune the pore size. ${ }^{33}$

When ethanol molecules are present in large enough amounts (either added or produced in hydrolysis of TEOS) in high $\mathrm{pH}$ conditions, the cubic structure of MCM-48 can be made by using CTAB. ${ }^{34}$ However, at too high temperature, the lamellar phase will result due to increased tail motion. An alternative way is to use the special Gemini surfactant so that the $\mathrm{g}$ value becomes larger; then one can make MCM-48 with high quality. The synthesis of $\mathrm{MCM}-48$ is often difficult, requiring precise control of $\mathrm{pH}$, temperature, and reaction time, because it needs kinetic quenching in the transformation $\mathrm{H}_{1} \rightarrow \mathrm{V}_{1} \rightarrow \mathrm{L}_{\alpha}$ to arrest the organization at the middle $\mathrm{V}_{1}$ phase. ${ }^{35}$ By using a surfactant mixture of $C_{n} T M A B$ and $C_{n}(E O)_{m}$, Ryoo et al. ${ }^{36}$ extended the stability of the cubic mesophase of MCM48.

The use of a counterion in the acidic synthesis of mesoporous silica influences the degree of surface charge screening. Nitric acid, with the highest binding strength counterion $\mathrm{NO}_{3}{ }^{-}$, tends to form very long micelles with $\mathrm{C}_{n} \mathrm{TMA}^{+}(\mathrm{n}=16-18)$. The high degree of screening of the surface charge of the micelles leads to a smaller effective surface area and a higher $\mathrm{g}$ value. The micelle grows into a long cylinder. $\mathrm{HNO}_{3}$ is a suitable acid source for preparing long silica ropes ${ }^{37}$ (Figure 4A). Macrospheres ${ }^{38}$ of centimeter scale from the quaternary ammonium surfactants can be also made by acidic synthesis (Figure $4 \mathrm{~B}$ ). The elongation of the surfactant micelles and the shear flow are the controlling factors in producing the morphology. 

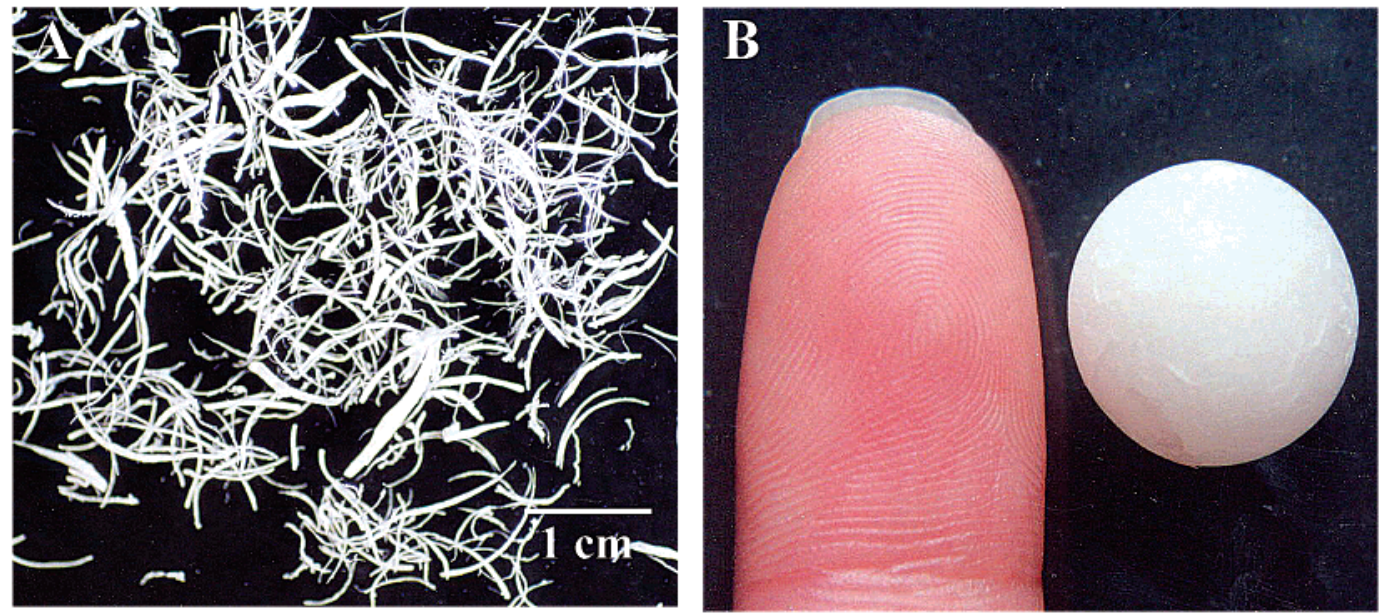

FIGURE 4. Photographs of the centimeter-size silica ropes $(A)$ and macrosphere $(B)$ prepared from $C_{18} T M A B-$ or $\left(C_{14} T M A B+D C_{12} D M A B\right)-$ $\mathrm{HNO}_{3}$-silicate-water composites, respectively.

Path B. The Lamellar Phase Route. In the first synthesis of mesoporous silica, ${ }^{39}$ the silica precursor was the high-charge-density kanemite, which has a strong tendency toward charge-shielding, decreasing the effective area of the headgroup of surfactants, and forms a lamellar structure of higher $g$ value ( $a_{0}$ smaller). After further silica condensation during hydrothermal treatment, the charge density on the silicas decreases, and then hexagonal mesophases with smaller $\mathrm{g}$ values were developed. This case involves a phase transition from $\mathrm{L}_{\alpha}$ to hexagonal $\mathrm{H}_{1}{ }^{40}$

During the $\mathrm{L}_{\alpha}$-to- $\mathrm{H}_{1}$ transformation, the silica wall must have a greater reconstruction to have charge balance with surfactants. Thus, the structure of the nanostructured composite is usually less ordered than that from the micellar route.

An illustrative example is the synthesis of MCM-41 using $\mathrm{C}_{18} \mathrm{TM} \mathrm{TB}$ and sodium silicates. ${ }^{5}$ In this system, assynthesized materials made at room temperature are in the $L_{\alpha}$ phase, while they are in the $H_{1}$ phase if they are made at $50^{\circ} \mathrm{C}$. After hydrothermal heating at $100^{\circ} \mathrm{C}$ for 2 days, both phases become hexagonal MCM-41. But the one transformed from the lamellar phase possesses poorer structure order. Hydrocarbon swelling can be used to make MCM-41 with larger pores. The solubilization of hydrocarbons gives a larger $\mathrm{V}$ but keeps $\mathrm{I}$ and $\mathrm{a}_{0}$ roughly constant. Thus, the increased packing parameter g gives a lamellar phase and transforms itself to $\mathrm{H}_{1}$ upon further silica condensation. This explains that pore expansion by hydrocarbon solubilization usually gives poorer structures of MCM-41.

Path C. The Nematic Phase Route. C.1. Characteriza tion of the Nematic Phase. In our laboratory, a "delayed neutralization process" was employed that allowed the silicate species to slowly grow and assemble with the surfactants, and a lyotropic nematic phase was found to be the intermediate phase in the synthesis. This route leads to many interesting hierarchical structures of MCM41, such as TWT and PWS. The lyotropic nematic phase is relatively rare. However, the system $\mathrm{C}_{14} \mathrm{TM} A B$ + water, similar to the system we used for MCM-41 synthesis, is known to exhibit a unique nematic phase. ${ }^{41}$ We synthe- sized MCM-41 by a system of $\mathrm{C}_{14} \mathrm{TMAB}-\mathrm{BuOH}$-silicate$\mathrm{H}_{2} \mathrm{O}$ composite formation. Butanol serves to decrease the rigidity of the mesophase, such that intricate micrometerscale morphologies can be developed.

When we performed in situ small-angle X-ray diffraction (SAXD) to monitor the mesophase changes of the $\mathrm{C}_{14^{-}}$ TMAB-BuOH - silicate- $\mathrm{H}_{2} \mathrm{O}$ composites under different acidification conditions (Figure 5A), an intermediate nematic $\mathrm{N}_{\mathrm{c}}$ phase (i.e., possessing long-range micellar orientation order but reduced translation order) with broader diffraction patterns was formed in the beginning (Figure 5A, I). A hexagonal phase $\left(H_{1}\right)$ then grows from the $\mathrm{N}_{\mathrm{c}}$ phase upon addition of more acid (Figure $5 \mathrm{~A}, \mathrm{II}-$ IV). To identify this $\mathrm{N}_{c}$ intermediate phase, a polarization optical microscope was used to observe the mesophases prepared from a liquid contact technique. From Figure $5 B$, we find a nematic phase $\left(N_{c}\right)$ at the boundary between an isotropic micellar solution $\left(L_{1}\right)$ and a hexagonal phase $\left(\mathrm{H}_{1}\right)$. The delayed neutralization process presents one distinct series of phase transformation (i.e., $\mathrm{N}_{\mathrm{c}} \rightarrow \mathrm{H}_{1}$ or $\mathrm{L}_{1}$ $\rightarrow \mathrm{N}_{\mathrm{c}} \rightarrow \mathrm{H}_{1}$ ) in forming the as-synthesized silicate/ surfactant complex. This nematic phase is soft and could bend itself into a spherulite form (previously called a vesicle), which is the basis of the TWT and PWS morphologies.

C.2. Morphology Tailoring through the Nematic Phase Let us first consider the formation of hollow spheres of MCM-41. Mesoporous silica hierarchical hollow spheres, with pillars inside, of diameter $5.0 \pm 1.0 \mu \mathrm{m}$ have been obtained from a solution of $\mathrm{C}_{14} \mathrm{TM} A B$, butanol, and sodium silicate by careful control of the acidification rate. ${ }^{15}$ The walls of these microspheres consist of a hexagonal arrangement of nanochannels in latitudinal directions. The whole process is driven by the following physicochemical transformation: silica condensation driving formation of nematic spherulites, and then nematic-tohexagonal transformation on the shell in turn driving pillar formation. The rigidity of the nematic mesophase of $\mathrm{C}_{14^{-}}$ $\mathrm{TMAB}-\mathrm{BuOH}-$ silicate$-\mathrm{H}_{2} \mathrm{O}$ depends on the $\mathrm{BuOH}$ content. When the amount of cosurfactant is reduced enough, the hexagonal structure is formed before bending itself 

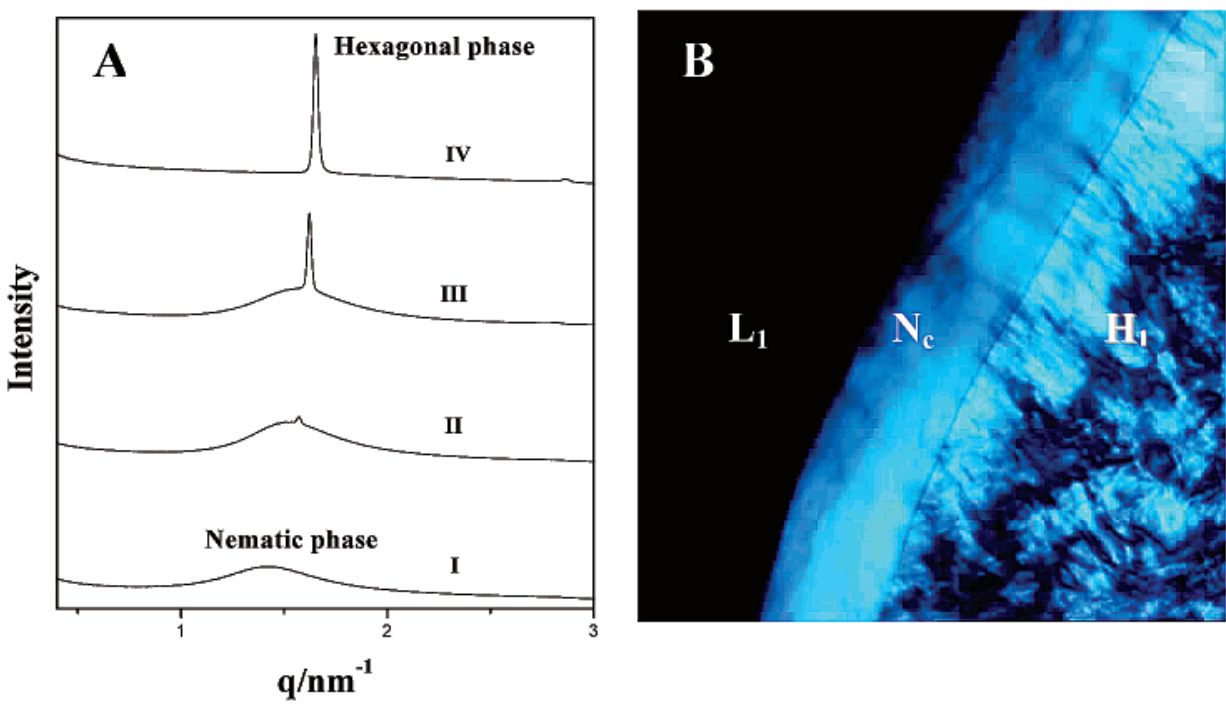

FIGURE 5. (A) SAXS spectrum of the $\mathrm{C}_{14} \mathrm{TM} A \mathrm{AB}-\mathrm{BuOH}-$ sodium silicate $-\mathrm{H}_{2} \mathrm{O}$ system at different acidification $\left(\mathrm{H}_{2} \mathrm{SO}_{4} / \mathrm{NaOH}=r\right) . \mathrm{I}, r=0$; $\mathrm{II}, r=0.10 ; \mathrm{III}, r=0.15 ; \mathrm{VI}, r=0.26$. (B) Cross-polarized optical micrograph of the nematic phase existing between the $\mathrm{H}_{1}$ and $\mathrm{L}_{1}$ phases in $\mathrm{C}_{14} \mathrm{TM} \mathrm{AB}-\mathrm{BuOH}-$ silicate composites.

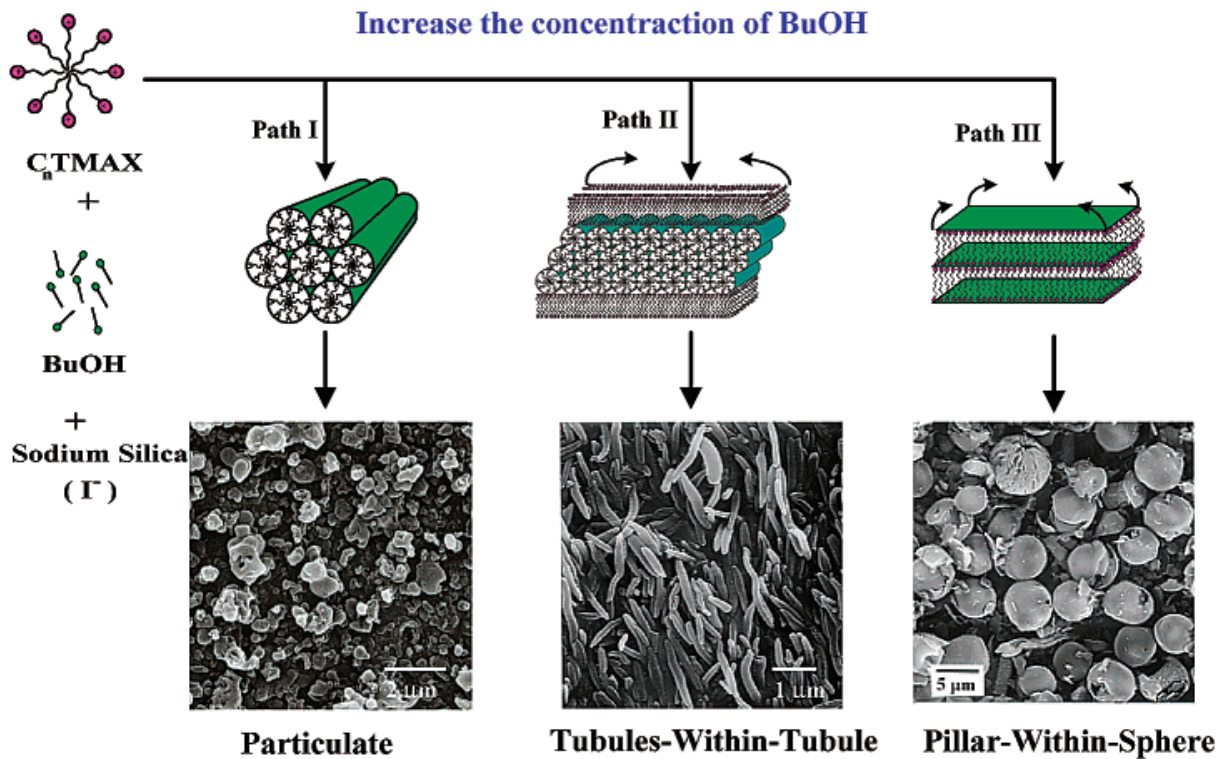

FIGURE 6. Schematic diagram describing the effect of the butanol $(\mathrm{BuOH})$ content, which can tailor the packing parameters and soften the rigidity of the silicate/surfactant mesostructure, on the mesophase transformations and the morphological evolution in the $\mathrm{C}_{14} \mathrm{TM} A \mathrm{AB}-$ silicate$\mathrm{BuOH}-\mathrm{H}_{2} \mathrm{O}$ composites.

into a tubular form. One then has TWT morphology. ${ }^{14}$ In Figure 6, a morphological evolution from particulate form (great rigidity) $\rightarrow$ TWT (medium rigidity) $\rightarrow$ spheres (small rigidity) is shown with the increase of the $\mathrm{BuOH} / \mathrm{C}_{14} \mathrm{TM} A B$ ratio at $27^{\circ} \mathrm{C}$.

The yield of these hierarchical structures of the mesoporous MCM -41 silica is high ( 98\%), and the radius $(0.2$ $\mu \mathrm{m})$ of the tubules-within-tubule or the diameter $(5.0 \pm$ $1.0 \mu \mathrm{m}$ ) of the spheres is quite uniform. This is because the hierarchical morphologies are created through equilibrium phase transformation rather than kinetic control. Our findings, in view of the recent developments in theories of complex fluids, suggest that the preparation of hierarchical ordered materials by the sol-gel method can be approached as a physicochemical phase transformation process.
C.3. Defect Control. If one examines the XRD data showing the nematic-to-hexagon phase transformation (Figure 5A), one sees shrinkage of lattice spacings during acidification. The expulsion of water accompanies the formation of the $\mathrm{H}_{1}$ phase, which leaves intraparticle water pools as defect voids in the MCM-41 formed (visible in Figure 2A). It was found that the extent of voids could be controlled in the synthesis. ${ }^{42}$ Figure 7A shows the $\mathrm{N}_{2}$ adsorption-desorption isotherms of the mesoporous materials in microparticle form (sample I), TWT structure (sample II), and particulates (sample III). The defectless MCM-41 silica (TEM micrograph in Figure 7B) possesses a sharp capillary condensation at $\mathrm{p} / \mathrm{p}_{0}$ of about 0.33 , while the TWT structure has an additional type- $\mathrm{H} 4$ hysteresis loop at $\mathrm{p} / \mathrm{p}_{0}=0.5-1.0$. In microtome TEM micrographs (Figures $7 \mathrm{C}$ and $2 \mathrm{~A}$ ), one can see many void spots in 

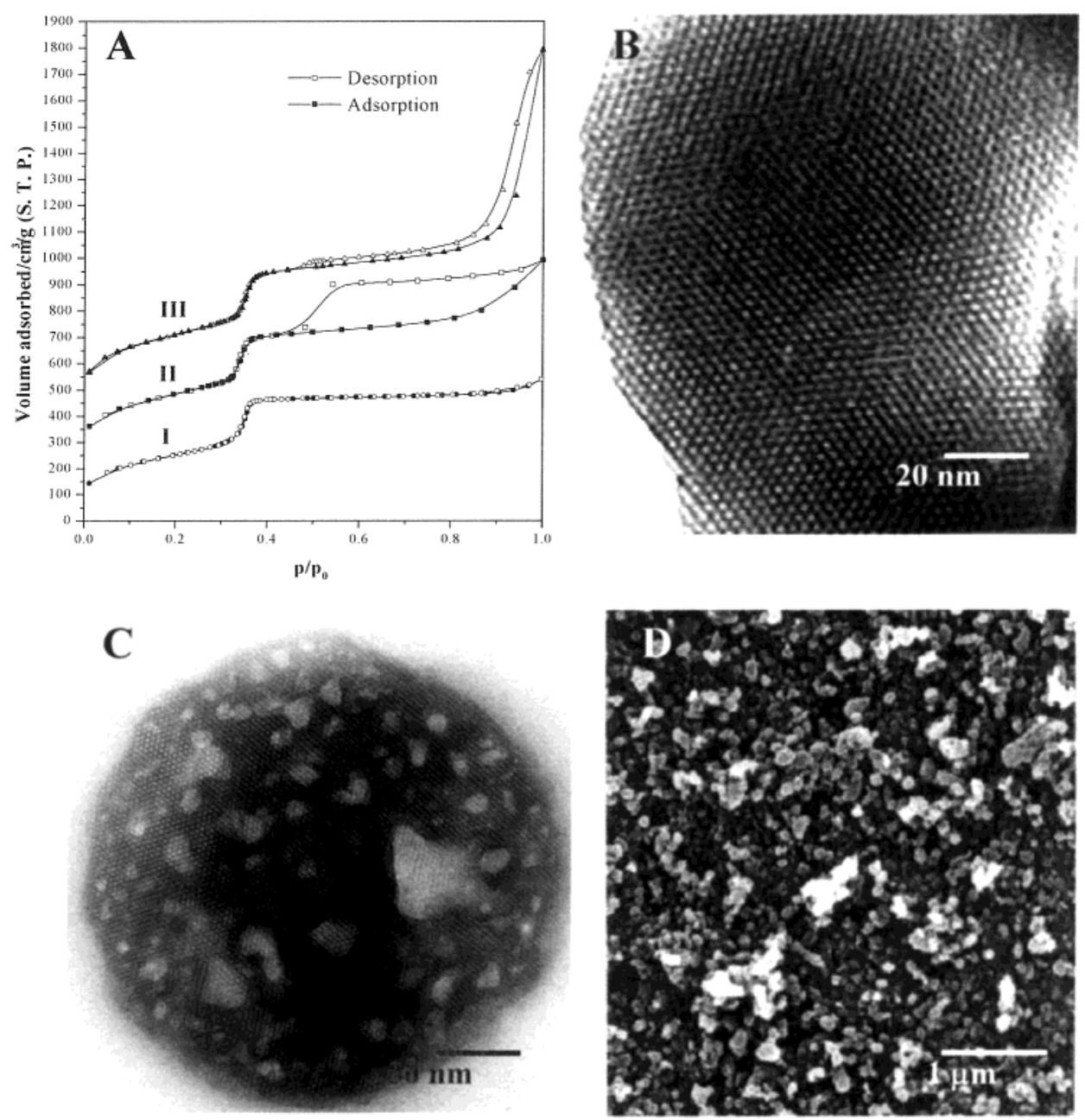

FIGURE 7. (A) $\mathrm{N}_{2}$ adsorption-desorption isotherms of the mesoporous silica and aluminosilicates samples obtained from $\mathrm{C}_{16} \mathrm{TM} A B-$ aluminosilicate $-\mathrm{H}_{2} \mathrm{O}$ systems by a delayed neutralization process. Sample I is a mesoporous silica $(\mathrm{Si} / \mathrm{Al}=\infty)$ with microparticle form; sample II is a mesoporous aluminosilicate ( $\mathrm{Si} / \mathrm{AI}=37$ ) with TWT hierarchical structure, and sample III is a mesoporous aluminosilicate (Si/AI $=37$ ) in the fine particulate form. (B) TEM micrograph of sample I. (C) M icrotome TEM micrograph of the sample II. (D) SEM micrograph of sample III.

addition to the nanochannels. The unusual adsorption hysteresis is associated with the pore blocking effect around the embedded voids in the framework structures. The void defects in the hexagonally ordered nanochannels matrix make the nanochannels become effectively interconnected and lead to better transport of molecules in the linear channels. It was shown that MCM-41, with extensive internal voids, is a better heterogeneous catalysis support. ${ }^{43}$

For the particulate form of M CM-41 (Figure 7D), there exists an additional vertical hysteresis loop in the adsorption/desorption curve, near $\mathrm{p} / \mathrm{p}_{0}=0.95-1.0$, attributed to textural mesoporosity. ${ }^{44}$ The texture pores are created from the packing of the nanoparticles. The presence of the interparticle pores also increases the diffusibility of the embedded molecules. ${ }^{45}$

\section{Postsynthesis Treatments}

A. Hydrothermal Treatments. Beside the hydrophobic core adjustments, high-temperature hydrothermal treatment can increase and stabilize the pores formed by the mesoporous materials. The main effect is the enlargement of the pore and its wall thickness. Hydrothermal treatments at $150{ }^{\circ} \mathrm{C}$ in mother liquid, pure water, or salt solution lead to controlled pore expansion. ${ }^{46}$

Summarizing observations from previous work, it seems that there are two kinds of aqueous media used for hydrothermal pore expansion, leading to different extents of pore expansion. ${ }^{47}$ If one uses mother liquor as the hydrothermal medium, then the high $\mathrm{pH}$ condition would activate surfactant decomposition and help silica hydrolysis. The silica undergoes extensive restructuring with the large neutral expander $\mathrm{N}, \mathrm{N}$-dimethylhexadecylamine (DMHA) solubilized in the surfactant organizations. ${ }^{48}$ On the other hand, pore expansion in water (thus a lower $\mathrm{pH}$ condition) usually leads to a minor expansion by about $30 \%$ and more complete siloxane bond condensation. This often leads to better stability. When salt is added in the hydrothermal treat-ment, the pore size varies with the kind of anion of the salt and their concentrations. An equilibrium distribution of surfactants inside the MCM-41 channels and in solution controls the 
pore size when the salts are varied. The anion binds with surfactant molecules in solution to shift the equilibrium of surfactant/silicate binding, leading to less surfactant and water in the pore and hence less pore expansion. The wall thickness variation agrees with a model of elastic annealing of the wall silica materials at high temperatures. ${ }^{49}$

On the other hand, the effect of ammonia hydrothermal treatment is to shift the equilibrium to stronger surfactant/ silicate binding and thus more pore expansion. ${ }^{50,51} \mathrm{Am}$ monia hydrothermal treatment of mesoporous silica ropes further results in formation of nanotubes. These nanotubes, looking rather like the multiwall carbon nanotubes, are the smallest tubules of mesoporous silica. ${ }^{52}$

In addition to the mesostructural tuning, hydrothermal treatment also can induce a topological transformation of micrometer-sized spheres. When a proper amount of sodium aluminate was added, hollow sphere of MCM-41 aluminosilicate with pinholes was obtained instead of the PWS MCM -41 silicas. $^{53}$

B. Reversible Interaction Transformation between Surfactant and Silica. It is noteworthy that the ionic interaction equilibrium in as-synthesized mesostructured silica/ surfactant can be shifted to a large extent. The ionic part of the structure is not rigid. Thus, a thermodynamically reversible transformation of the silica-surfactant interactions could be set up by further adjusting the $\mathrm{pH}$ value as follows:

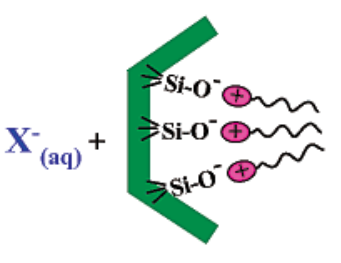

Strong electrostatic interaction

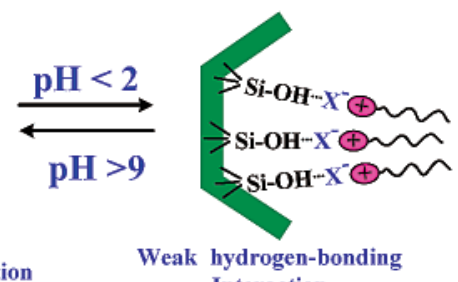

Interaction
Thus, one can start from alkaline or acidic synthesis to manufacture certain unique mesoporous structure and morphology, and then transform the interactions. On the basis of this concept, one can design a convenient and economic path for getting the mesoporous products to match the desired applications.

\section{Conclusion}

In conclusion, the control and understanding of the structure of mesoporous silica on both nanometer and micrometer scales can be approached in terms of the physical chemistry of silica/ surfactant organization. One can exploit this to improve the stability and surface modification. Surface functionalization will give us the ability to design the environments of nanoreactors. The use of MCM-41 fibers as hosts for extrusion polymerization of polyethylene is an excellent example. ${ }^{54}$ The discovery of a rich and intricate family of topologies for mesoporous silica points to future development of designed morphogenesis of complex biomimetic oxide materials. The development needs better integration of our knowledge of sol-gel chemistry, surfactant liquid crystalline organization, and the physics of soft matter. The goal is not only intellectually challenging but also important in enriching our ability to build complex inorganic/organic nanostructured materials in a bottom-up approach.

We thank the many hard-working students in the laboratory of C.-Y.M. in the past five years. This research was financially supported by the Chinese Petroleum Co., Ministry of Education, and the National Science Council of Tai wan.

\section{References}

(1) Kresge, C. T.; Leonowicz, M. E.; Roth, W. J .; Vartuli, J . C.; Beck, J. S. Ordered mesoporous molecular sieves synthesized by a liquid-crystal template mechanism. Nature 1992, 359, 710-713.

(2) Ying, J . Y.; Mehnert, C. P.; Wong, M. S. Synthesis and Applications of supramolecular-templated mesoporous materials. Angew. Chem., Int. Ed. 1999, 38, 56-77.

(3) Evans, D. F.; Wennerstrom, H. The Colloid Domain; VCH: New York, 1994

(4) Huo, Q.; Margolese, D. I.; Stucky, G. D. Surfactant control of phases in the synthesis of mesoporous silica-based materials. Chem. Mater. 1996, 8, 1147-1160.

(5) Lin, H. P.; Cheng, S.; Mou, C. Y. Effect of delayed neutralization on the synthesis of mesoporous molecular sieve MCM-41. Microporous Mater. 1997, 10, 111-121.

(6) Liu, Y.; Karkamkar, A.; Pinnavaia, T. J . Redirecting the assembly of hexagonal MCM-41 into cubic MCM-48 from sodium silicate without the use of an organic structure modifier. Chem. Commun. 2001, 1822-1823.

(7) Tolbert, S. H.; Landry, C. C.; Stucky, G. D.; Chmelka, B. F.; Norby, P.; Hanson, J . C.; Monnier, A. Phase transition in mesostructured silica/surfactant composites: Surfactant packing and the role of charge density matching. Chem. Mater. 2001, 13, 2247-2256.

(8) Tanev, P. T.; Pinnavaia, T. J . Biomimetic templating of porous lamellar silica by vesicular surfactant assemblies. Science $\mathbf{1 9 9 6}$ 271, 1267-1269.

(9) Zhao, D.; Feng, J.; Huo, Q.; Melosh, N.; Fredrickson, G. H.; Chmelka, B. F.; Stucky, G. D. Copolymer synthesis of mesoporous silica with periodic 50-300 Angstrom pores. Science 1998, 279, $548-552$.

(10) Iler, R. K. The chemistry of silica: solubility, polymerization, colloid and surface properties, and biochemistry; Wiley: New York, 1979.

(11) Di Renzo, F.; Testa, F.; Chen, J . D.; Cambon, H.; Galarneau, A Plee, D.; Fajula, F. Texture control of micelle-templated mesoporous silicates: the effect of co-surfactant and alkalinity. Microporous Mesoporous Mater. 1999, 28, 437-446.

(12) Mou, C. Y.; Lin, H. P. Control of morphology in synthesizing mesoporous silica. Pure Appl. Chem. 2000, 72, 137-14.

(13) Lin, H. P.; Mou, C. Y. Hollow tubules-within-tubule structure of mesoporous molecular sieves MCM-41. Science 1996, 273, 765768.

(14) Lin, H. P.; Cheng, S.; Mou, C. Y. Mesoporous molecular sieves MCM-41 with a new hollow tubular morphology. Chem. Mater. 1998, 10, 581-589.

(15) Lin, H. P.; Cheng, Y. R.; Mou, C. Y. Hierarchical order in hollow spheres of mesoporous silicates. Chem. Mater. 1998, 10, 37723776.

(16) Lin, H. P.; Mou, C. Y. Studies on mesoporous self-organizing aluminosilica. J. Cluster Sci. 1999, 10, 271-293.

(17) Lin, H. P.; et al. The synthesis and application of the mesoporous molecular sieves MCM-41. J. Chin. Chem. Soc. 1999, 46, 495505

(18) Lin, H. P.; Cheng, S.; Mou, C. Y. Synthesis of thermally stable MCM-41 at ambient temperature. J. Chin. Chem. Soc. 1996, 43, 375-378.

(19) Ryoo, R.; Kim, J. M. Structural order in MCM-41 controlled by shifting silicate polymerization equilibrium. J. Chem. Soc., Chem. Commun. 1995, 711.

(20) Echchahed, B.; Morin, M.; Blais, S.; Badiei, A. R.; Berhault, G.; Bonneviot, L. Ion mediation and surface charge density in phase transition of micelle templated silica. Microporous Mesoporous Mater. 2001, 44, 53-63.

(21) Lin, H. P.; Kao, C. P.; Mou, C. Y. Counterion and alcohol effect on mesoporous MCM-41 silica materials. Microporous Mesoporous Mater. 2001, 48, 135-141.

(22) Rubingh, D. N.; Holland, P. M. Cationic surfactant: Physical chemistry; Surfactant Science Series 37; Marcel Dekker: New York, 1991. 
(23) Zhang, Z.; Han, Y.; Zhu, L.; Wang, R.; Yu, Y.; Qiu, S.; Zhao, D.; Xiao, F. S. Strongly acidic and high-temperature hydrothermally stable mesoporous aluminosilicates with ordered hexagonal structure. Angew. Chem., Int. Ed. 2001, 40, 1258-1262.

(24) Das, D.; Tsai, C. M.; Cheng, S. Improvement of hydrotherma stability of MCM-41 mesoporous molecular sieves. Chem. Commun. 1999, 473.

(25) Lin, H. P.; Kao, C. P.; Liu, S. B.; Mou, C. Y. Counterion effect in acid synthesis of mesoporous silica materials. J. Phys. Chem. B 2000, 104, 7885-7894

(26) Zhao, D.; Yang, P.; Huo, Q.; Chmelka, B. F.; Stucky, G. D. Topological construction of mesoporous materials. Curr. Opin. Solid State Mater. Sci. 1998, 3, 111-121.

(27) Bruinsma, P.J .; Kim, A. Y.; Liu, J .; Baskaran, S. Mesoporous silica synthesized by solvent evaporation spun fibers and spray-dried hollow spheres. Chem. Mater. 1997, 9, 2507-2512.

(28) Yang, H.; Coombs, N.; Sokolov, I.; Ozin, G. A. Free-standing and oriented mesoporous silica films grown at the air-water interface. Nature 1996, 381, 589-592.

(29) Coleman, N. R. B.; Attard, G. S. Ordered mesoporous silicas prepared from both micellar solutions and liquid crystal phases. Microporous Mesoporous Mater. 2001, 44, 73-80.

(30) Feng, P.; Bu, X.; Stucky, G. D.; Pine, D. J . Monolithic Mesoporous Silica Templated by Microemulsion Liquid crystal. J . Am. Chem. Soc. 2000, 122, 994-995.

(31) Chen, C.; Li, H.; Davis, M. E. Studies on mesoporous materials: $1 \&$ 2. Microporous Mater. 1993, 2, 17-34.

(32) Lin, H. P.; Cheng, Y. R.; Liu, S. B.; Mou, C. Y. The effect of 1-alkanols addition on the structural ordering and morphology of mesoporous silicate MCM-41. J . Mater. Chem. 1999, 9, 11971201.

(33) Cheng, Y. R.; Lin, H. P.; Mou, C. Y. Control of mesostructure and morphology of surfactant-templated silica in mixed surfactant system. Phys. Chem. Chem. Phys. 1999, 1, 5051-5058.

(34) Gallis, K. W.; Landry, C. C. Synthesis of MCM-48 by phase transformation process. Chem. Mater. 1997, 9, 2035-2038.

(35) Xu, J .; Luan, Z.; He, H.; Zhou, W.; Kevan, L. A reliable synthesis of cubic mesoporous MCM-48 molecular sieves. Chem. Mater. 1998, 10, 3690-3698.

(36) Ryoo, R.; J oo, S. H.; Kim, J . M. Energetically favored formation of MCM-48 from cationic-neutral surfactant mixtures. J . Phys. Chem. B 1999, 103, 7435-7440.

(37) Lin, H. P.; Liu, S. B.; Mou, C. Y.: Tang, C. Y. Hierarchical organization of mesoporous MCM-41 ropes. Chem. Comm. 2000, 583-584.

(38) Kao, C. P.; Lin, H. P.; Mou, C. Y. Synthesis of elastic macrospheres of silica-surfactant composites. J. Phys. Chem. Solids 2001, 62, 1555-1559.

(39) Inagaki, S.; Fukushima, Y.; Kuroda, K. Synthesis of highly ordered mesoporous materials from a layered polysilicates. J. Chem. Soc., Chem. Commun. 1993, 680-681.
(40) Monnier, A.; Schuth, F.; Huo, Q.; Kumar, D.; Margolese, D. Maxwell, R. S.; Stucky, G. D.; Krishnamurty, M.; Petroff, P.; Firouzi, A.; J anicke, M.; Chmelka, B. F. Cooperative formation of inorganicorganic interfaces in the synthesis of silicate mesostructures. Science 1993, 261, 1299.

(41) Photinos, P.; Xu, S. Y.; Saupe, A. Experimental study of the micellar nematic phase of tetradecyltrimethylammonium bromide. Phys. Rev. A 1990, 42, 865-871.

(42) Lin, H. P.; Wang, S. T.; Mou, C. Y.; Tang, C. Y. Void defects in mesoporous aluminosilicate MCM-41. J . Phys. Chem. B 2000, 104, 8967-8975.

(43) Wong, S. T.; Lin, H. P.; Mou, C. Y. MCM-41 tubule with 3-dimensional pore size system: Catalyst support in the dehydrogenation of ethylbenzene. Appl. Catal. 2000, 198, 103-114.

(44) Gregg, S. J .; Sing, K. S. W. Adsorption, surface area and porosity Academic Press: London, 1982.

(45) Pauly, T. R.; Liu, Y.; Pinnavaia, T. J .; Billinge, S.J . L.; Rieker, T. P. Textural mesoporosity and the catalytic activity of mesoporous molecular sieves with wormhole framework structures. J. Am. Chem. Soc. 1999, 121, 8835-8842.

(46) Kruk, M.; J aroniec, M.; Sayari, A. A unified interpretation of hightemperature pore size expansion processes in MCM-41 mesoporous silicas, J. Phys. Chem. B 1999, 103, 4590-4598.

(47) Lin, H. P.; Mou, C. Y. Salt effect in post-synthesis hydrothermal treatment of MCM-41. Microporous Mesoporous Mater., in press.

(48) Sayari, A. Unprecedented expansion of the pore size and volume of periodic mesoporous silica. Angew. Chem., Int. Ed. 2000, 39, 2920-2922.

(49) Gross, A. F.; Ruiz, E. J : Tolbert, S. H. Effect of framework polymerization on the phase stability of periodic silica/surfactant nanostructured composites. J . Phys. Chem. B 2000, 104, 54485461.

(50) Lin, H. P.; Mou, C. Y.; Liu, S. B. Ammonia hydrothermal improvement of mesoporous silica structure synthesized from acidic route. Chem. Lett. 1999, 12, 1341-1342.

(51) Lin, H. P.; Liu, S. B.; Mou, C. Y.; Tang, C. Y.; Lin, C. Y. Postsynthesis treatment of acid-made mesoporous silica materials by ammonia hydrothermal process. Microporous Mesoporous Mater. 2001, 44, 129-137.

(52) Lin, H. P.; Mou, C. Y.; Liu, S. B. Formation of mesoporous silica nanotubes. Adv. Mater. 2000, 12, 103-106.

(53) Lin, H. P.; Mou, C. Y.; Liu, S. B.; Tang, C. Y. Hollow spheres of MCM-41 aluminosilicate with pinhole. Chem. Commun. 2001 1970-1971.

(54) Kageyama, K.; Tamazawa, J . I.; Aida, T. Extrusion polymerization: catalyzed synthesis of crystalline linear polyethylene nanofibers within a mesoporous silica. Science 1999, 285, 2113-2115.

AR000074F 